\title{
Synthesis and photovoltaic application of platinum- modified conducting aligned nanotube fiber
}

\author{
YiShu Jiang, Hao Sun and HuiSheng Peng*
}

\begin{abstract}
Platinum-modified carbon nanotube (CNT) fibers with controlled platinum weight percentages were synthesized via an electrochemical deposition method. Platinum nanoparticles can be uniformly deposited on the surface of the aligned CNTs in the fiber, which possesses an efficient improved catalytic activity in the reduction of $\mathrm{I}_{3}^{-} / \mathrm{I}^{-}$compared with other fiber materials such as a carbon fiber without the aligned nanostructure. The hybrid CNT fiber was further used as a counter electrode to fabricate fiber-shaped dye-sensitized solar cell (DSSC). A maximal power conversion efficiency of $8.10 \%$ was achieved, compared with that of $4.91 \%$ for a bare aligned CNT fiber and $5.50 \%$ for a platinum-modified carbon fiber as the counter electrode under the same condition.
\end{abstract}

\section{INTRODUCTION}

Due to the unique structure, aligned carbon nanotube (CNT) fibers have been widely demonstrated to be flexible, strong and electrically conducting, which offers them promising applications as a new family of electrode materials [1-7]. They were recently explored to fabricate wearable photovoltaic devices such as dye-sensitized solar cells (DSSCs) in a fiber shape [8-11]. Although intriguing advantages of such fiber electrode materials and devices have been demonstrated, the power conversion efficiencies of the fiber-shaped DSSCs are generally lower than $5 \%$ [8-11]. A main reason is derived from the relatively lower catalytic activity of the CNT compared with the conventional platinum, particularly, platinum nanoparticles. Therefore, it is necessary to further enhance the catalytic property of the CNT fiber. Here an effective strategy is proposed to modify the aligned CNT fibers by incorporating a second phase with higher catalytic activity. Uniform platinum nanoparticles can be deposited onto the CNTs with controlled weight percentages through a double potential step electrochemical deposition. The resulting hybrid fiber serves as a counter electrode to fabricate the fiber-shaped DSSC with much higher power conversion efficiency than a bare CNT fiber and platinum-modified carbon fiber under the same condition.

\section{RESULTS AND DISCUSSION}

Aligned CNT fibers with a uniform diameter of $\sim 30 \mu \mathrm{m}$ were continuously dry-spun from a spinnable CNT array (Fig. S1). As widely explored, the CNT bundles were highly aligned with each other with voids of typically tens of nanometers (Fig. S2). The aligned structure in the fiber is important to extend the remarkable properties of the individual CNTs to the macroscopic scale [12-15], while the voids are critical to incorporate a second phase, e.g., a wide variety of polymers were incorporated into the voids through a solution process or electrochemical deposition [16].

Platinum nanoparticles were then electrochemically deposited on the aligned CNT fibers via a double potential step method [17]. The aqueous electrolyte was composed of $1 \mathrm{mM} \mathrm{K}_{2} \mathrm{PtCl}_{6}$ and $0.1 \mathrm{M} \mathrm{KCl}$, with a platinum wire and $\mathrm{Ag} / \mathrm{AgCl} / \mathrm{KCl}$ electrode used as counter and reference electrodes, respectively. The first potential at $0.5 \mathrm{~V}$ was maintained for $10 \mathrm{~s}$ and the second step at $-0.7 \mathrm{~V}$ was maintained for $10 \mathrm{~s}$. By repeating 2, 5, 10 and 20 times of the double potential steps, platinum/CNT hybrid fibers with increasing platinum weight percentages of $3.8 \%, 9.5 \%$, $20.6 \%$ and $44.6 \%$ were synthesized (Fig. S3). The weight percentages were calculated from the consumed charge during the electrochemical deposition $[18,19]$. With the increasing platinum weight percentage from $3.8 \%$ to $44.6 \%$, the nanoparticles became more uniform in size but with increasing diameters (Figs 1 and S4). Beyond the critical point at $44.6 \%$, no obvious distribution variations were observed, although the nanoparticle diameters were continuously increased to form larger aggregates. The microstructure of the deposited platinum nanoparticles was further verified by transmission electron microscopy (TEM), and the fringe spacing was measured to be $0.23 \mathrm{~nm}$, corresponding to the interplanar separation between the $\{111\}$ planes of platinum (Fig. S5). It should be noted that the aligned structure of CNTs is well retained after the electrochemical deposition of platinum nanoparticles. In other words, the high mechanical and electrical properties were maintained

State Key Laboratory of Molecular Engineering of Polymers, Department of Macromolecular Science and Laboratory of Advanced Materials, Fudan University, Shanghai 200438, China

*Corresponding author (email: penghs@fudan.edu.cn) 

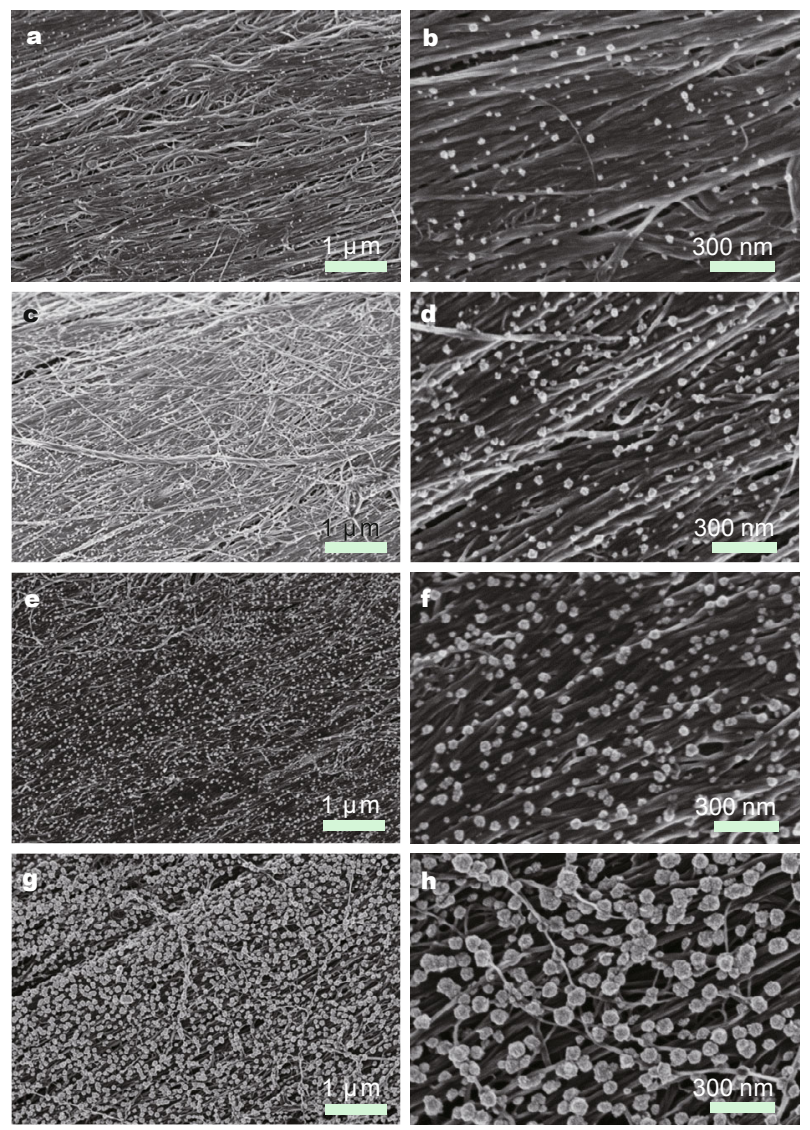

Figure 1 Scanning electron microscopy (SEM) images of platinum/CNT hybrid fibers with increasing platinum weight percentages of $(a, b) 3.8 \%$, (c, d) $9.5 \%$, (e, f) $20.6 \%$ and (g, h) $44.6 \%$ at low and high magnifications.

in the resulting hybrid CNT fibers. For instance, the tensile strengths and electrical conductivities were measured on the level of $10^{2}-10^{3} \mathrm{MPa}$ and $10^{2}-10^{3} \mathrm{~S} \mathrm{~cm}^{-1}$, respectively, which are necessary for their electronic applications and would be essential for the fiber-shaped DSSC.

The catalytic activities of the bare CNT and the platinum/CNT hybrid fibers with increasing platinum weight percentages in the redox reaction of $\mathrm{I}_{3}^{-} / \mathrm{I}^{-}$were compared by cyclic voltammetry (Fig. 2a). Two pairs of oxidation/reduction peaks are observed in every cyclic voltammogram, in which the left one is corresponding to the redox reaction of $\mathrm{I}_{3}^{-} / \mathrm{I}^{-}$. As generally accepted, a lower peak-to-peak voltage $\left(V_{\mathrm{pp}}\right)$ separation indicates a higher catalytic activity for the counter electrode $[20,21]$. The $V_{\mathrm{pp}}$ reduces monotonically from 0.62 to $0.40 \mathrm{~V}$, indicating continuously enhanced catalytic activities of the hybrid fibers with the increasing platinum contents (inset in Fig. 2a).

The hybrid CNT fiber was used as a counter electrode to fabricate fiber-shaped DSSCs. The typical structure is schematically shown in Fig. 3a. A Ti wire with a diameter of 127 $\mu \mathrm{m}$ was modified with $\mathrm{TiO}_{2}$ nanotube arrays, followed by adsorbing N719 dye to serve as the photoanode. An elec-
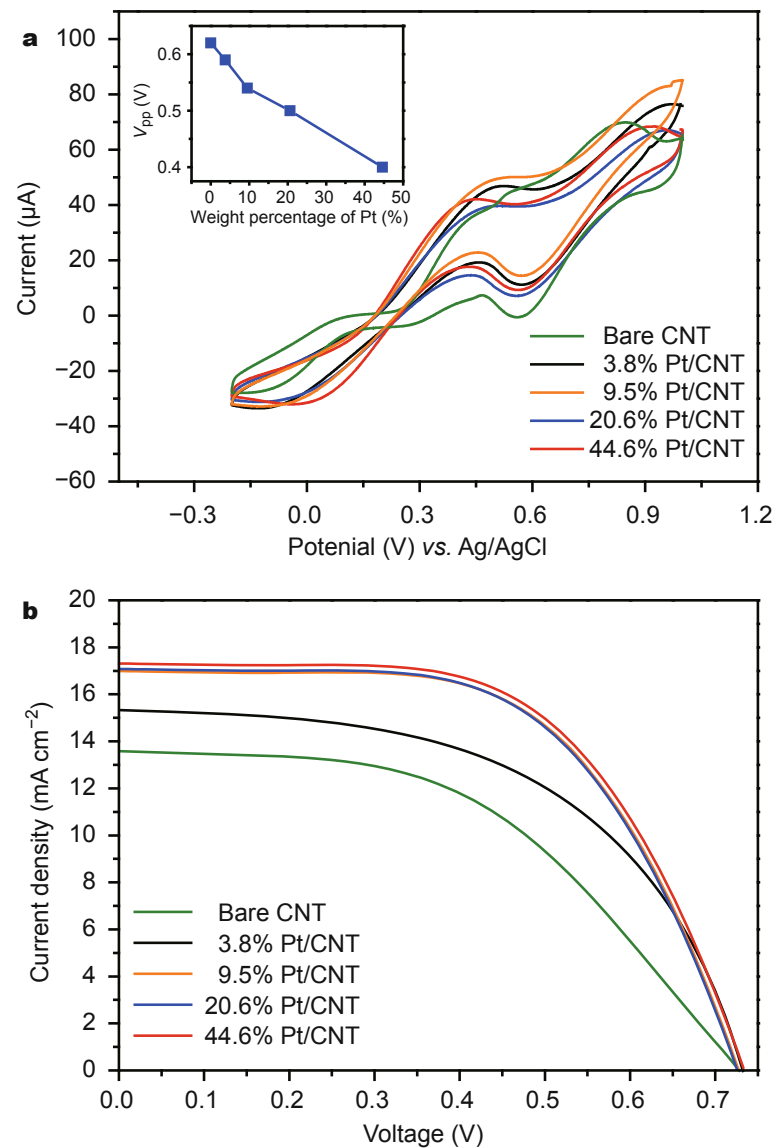

Figure 2 (a) Comparison on catalytic activities of platinum/CNT fiber electrodes with increasing platinum weight percentages. (b) Comparison on $J-V$ curves of fiber-shaped DSSCs based on platinum/CNT fiber electrodes with increasing platinum weight percentages as the counter electrodes under AM 1.5 illumination.

trochemically anodic oxidation method was performed to perpendicularly grow $\mathrm{TiO}_{2}$ nanotube arrays on the surface of Ti wire, and a diameter of $\sim 156 \mu \mathrm{m}$ was observed for the photoanode after anodic oxidation (Fig. S6a). The $\mathrm{TiO}_{2}$ nanotubes show a uniform diameter and smooth tube wall, which is favorable for the dye adsorption and electron transport (Fig. S6b). A bare CNT fiber or platinum-modified hybrid fiber was then twisted onto the photoanode with an average pitch of $\sim 500 \mu \mathrm{m}$, and a liquid electrolyte containing redox couple of $\mathrm{I}_{3}^{-} / \mathrm{I}^{-}$was used as the electrolyte. The as-fabricated device was sealed in a transparent plastic tube with two electrodes extracted and modified with indium before characterization. The working mechanism of the fiber-shaped DSSC was previously described [9-11] and further summarized in Fig. 3b. Under illumination, the dye molecules capture photons and inject electrons into the conduction band of the $\mathrm{TiO}_{2}$ nanotubes. The electrons migrate along the $\mathrm{TiO}_{2}$ nanotube, reach to the $\mathrm{Ti}$ wire, and travel throughout the external circuit. The route for elec- 

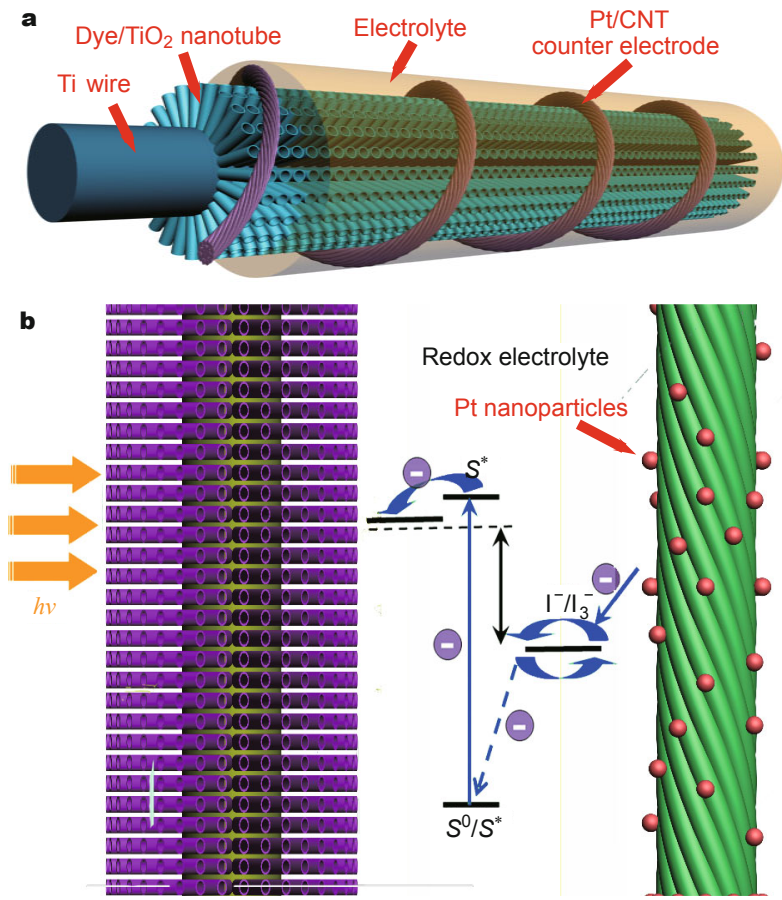

Figure 3 Schematic illustration of the structure (a) and working mechanism (b) of the fiber-shaped DSSC based on a platinum/CNT fiber electrode.

tron transport inside the cell is closed by the redox cycle in the electrolyte. $\mathrm{I}_{3}^{-}$ions obtain electrons to be reduced to $\mathrm{I}^{-}$ions at the counter electrode. $\mathrm{I}^{-}$ions release electrons to regenerate the oxidized dye molecules.

Typical $J-V$ curves are exhibited in Fig. $2 b$ under AM 1.5 illumination. The open-circuit voltage $\left(V_{\text {oc }}\right)$ remains almost the same of $0.73 \mathrm{~V}$ for all curves. However, the short circuit current density $\left(J_{\text {sc }}\right)$ increases from 13.60 to 16.99 $\mathrm{mA} \mathrm{cm}{ }^{-2}$ and the fill factor (FF) increases from 0.50 to 0.64 with the increasing platinum weight percentage from 0 to $9.5 \%$. With the further increase to $44.6 \%$, the FF remains almost unchanged and the $J_{\text {sc }}$ slightly increases to 17.29 $\mathrm{mA} \mathrm{cm}{ }^{-2}$. A maximal power conversion efficiency of $8.10 \%$ is achieved at the platinum weight percentage of $44.6 \%$, much higher than $4.91 \%$ for a bare CNT counter electrode. It should be noted that both distributions and sizes of platinum nanoparticles are important to the device performances. With the increasing platinum weight percentage from 0 to $9.5 \%$, platinum nanoparticles become more uniform with increasing sizes. The catalytic activities of the resulting hybrid fibers increase with higher photovoltaic performances. With the further increase in the weight percentage to $44.6 \%$, the distribution remains the same, while the nanoparticle sizes are further increased. A continuous improvement in the catalytic activity is observed while the power conversion efficiency slightly increases.

The high photovoltaic performances of the fiber-shaped
DSSC can be attributed to the combined advantages of the aligned CNTs and the platinum nanoparticles. The aligned CNTs provide an effective interaction with platinum due to the high specific surface area and the voids among them. The small platinum nanoparticles largely increase the catalytic activity of the resulting counter electrode, leading to a more efficient catalysis for the redox reaction of $\mathrm{I}_{3}^{-} / \mathrm{I}^{-}$. To verify the advantages of the aligned CNTs as substrates, carbon fiber was also used to deposit platinum nanoparticles under the same condition. Platinum aggregates appear less uniform with diameters of hundreds of nanometers, which indicates a less effective interaction between the carbon fiber and the platinum nanoparticles (Fig. 4). The deposition of platinum was further verified by the element mapping and intensity distribution (Fig. S7). As a result, the fiber-shaped DSSC based on platinum/carbon fiber counter electrode with the platinum weight percentage of $44.6 \%$ exhibites a much lower power conversion efficiency of $5.5 \%$.

The photovoltaic performances of these fiber-shaped DSSCs based on platinum/CNT hybrid fiber electrodes are independent on the angle of the incident light. A fiber-shaped DSSC was measured by rotating the fiber device while stabilizing the incident light (Fig. S9). The variation of the power conversion efficiency is below 5\%, demonstrating that the platinum nanoparticles are also uniformly deposited across the CNT fiber.

\section{CONCLUSION}

In summary, platinum-modified CNT fibers with tunable platinum weight percentages were prepared through an electrochemical deposition method. Platinum nanoparticles are uniformly distributed on the aligned CNT fibers to show high catalytic activities. These hybrid fibers were further used to fabricate fiber-shaped DSSCs to verify the
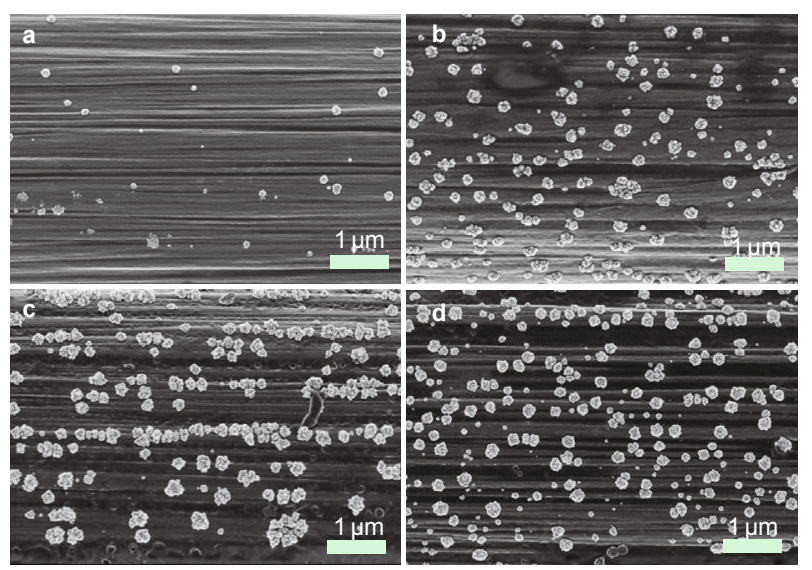

Figure 4 SEM images of platinum-modified carbon fibers with increasing platinum weight percentages of (a) $3.8 \%$, (b) $9.5 \%$, (c) $20.6 \%$ and (d) $44.6 \%$. 
high photovoltaic performance. A maximal power conversion efficiency of $8.10 \%$ is achieved and much exceeds that of a bare CNT fiber and platinum-deposited carbon fiber electrodes.

\section{EXPERIMENTAL SECTION}

\section{Preparation of the aligned CNT fiber}

The synthesis of the spinnable CNT array was previously reported $[22,23]$. Briefly, it was synthesized by a chemical vapor deposition method with $\mathrm{Fe}(1.2 \mathrm{~nm}) / \mathrm{Al}_{2} \mathrm{O}_{3}(3 \mathrm{~nm})$ on a silicon substrate as the catalyst at $740^{\circ} \mathrm{C}$. Ethylene served as the carbon source, and a mixed gas of $\mathrm{Ar}$ and $\mathrm{H}_{2}$ were used as the carrier gas. The flow rates of $\mathrm{Ar}, \mathrm{H}_{2}$, and $\mathrm{C}_{2} \mathrm{H}_{4}$ were typically 400,30 , and $90 \mathrm{sccm}$, respectively. The aligned CNT sheet can be continuously drawn out of a spinnable CNT array, followed by twisting into an aligned CNT fiber.

\section{Synthesis of platinum-modified CNT and carbon fiber}

An electrochemical double potential step method was used to synthesize hybrid fibers in a glass container at room temperature [17]. The aqueous electrolyte was composed of $1 \mathrm{mM} \mathrm{K}_{2} \mathrm{PtCl}_{6}$ and $0.1 \mathrm{M} \mathrm{KCl}$, with a platinum wire and $\mathrm{Ag} / \mathrm{AgCl} / \mathrm{KCl}$ electrode used as counter and reference electrodes, respectively. The platinum-modified carbon fiber can be prepared by using carbon fiber in replacement of CNT fiber with all the other conditions remaining the same. The weight percentages of platinum nanoparticles were calculated from the consumed charge during electrochemical deposition [19]. The obtained fibers were washed with deionized water and then dried at room temperature prior to use.

\section{Fabrication of the fiber-shaped DSSC}

$\mathrm{TiO}_{2}$ nanaotube-modified $\mathrm{Ti}$ wire was prepared by an anodic oxidation method at the voltage of $60 \mathrm{~V}$ for $6 \mathrm{~h}$ with 0.3 wt.\% $\mathrm{NH}_{4} \mathrm{~F} /$ ethylene glycol solution containing 8 wt.\% $\mathrm{H}_{2} \mathrm{O}$ as electrolyte. Ti wire and $\mathrm{Pt}$ sheet served as anode and cathode, respectively. After anodic oxidation, the resulting wires were washed with deionized water, heated to $500^{\circ} \mathrm{C}$ for $1 \mathrm{~h}$ and annealed in the air. The treated wire was immersed in a $40 \mathrm{mM} \mathrm{TiCl}_{4}$ aqueous solution at $70^{\circ} \mathrm{C}$ for 30 min, followed by rinsing with deionized water and annealing at $450^{\circ} \mathrm{C}$ for $30 \mathrm{~min}$. After the temperature dropped to $120^{\circ} \mathrm{C}$, it was immersed into $0.3 \mathrm{mM} \mathrm{N719}$ solution in a mixed solvent of dehydrated acetonitrile and tert-butanol (volume ratio of $1 / 1$ ) for $16 \mathrm{~h}$. The resulting fiber electrodes were twisted with bare CNT fiber, platinum-modified CNT fiber or platinum-modified carbon fiber. These fiber-shaped DSSCs were inserted into a transparent flexible plastic tube (diameter of $500 \mu \mathrm{m}$ ) with two fiber elec- trodes extracted and modified with indium. The electrolyte (containing 0.1 M LiI, 0.05 $\mathrm{M} \mathrm{I}_{2}, 0.6 \mathrm{M} \mathrm{1,2-dimethyl-3-pro-}$ pylimidazolium iodide and $0.5 \mathrm{M}$ 4-tertbutyl-pyridine in dehydrated acetonitrile) was injected into the tube and the two ends were sealed before characterization (Fig. S8).

\section{Characterization}

The structures were characterized by SEM (Hitachi FESEM S-4800 operated at $1 \mathrm{kV}$ ). The cyclic voltammetry was performed on a $\mathrm{CHI} 660 \mathrm{a}$ electrochemical workstation in an acetonitrile solution containing $5 \mathrm{mM}$ LiI, 0.5 $\mathrm{mM} \mathrm{I}_{2}$ and $0.05 \mathrm{M} \mathrm{LiClO}_{4}$ with a scan rate of $50 \mathrm{mV} \mathrm{s}^{-1}$ through a three-electrode setup. $J$ - $V$ curves were recorded with a Keithley 2420 Source Meter under illumination (100 $\mathrm{mW} \mathrm{cm} \mathrm{cm}^{-2}$ ) of the simulated AM1.5 solar light from a solar simulator (Oriel-Sol3A 94023A equipped with a $450 \mathrm{~W} \mathrm{Xe}$ lamp and an AM1.5 filter). The light intensity was calibrated using a reference Si solar cell (Oriel-91150).

Received 31 January 2015; accepted 13 March 2015; published online 30 March 2015

1 Dalton AB, Collins S, Munoz E, et al. Super-tough carbon-nanotube fibres. Nature, 2003, 423: 703-703

2 Ren J, Zhang Y, Bai W, et al. Elastic and wearable wire-shaped lithiumion battery with high electrochemical performance. Angew Chem Int Ed, 2014, 126: 7998-8003

3 Lee JA, Shin MK, Kim SH, et al. Ultrafast charge and discharge biscrolled yarn supercapacitors for textiles and microdevices. Nat Commun, 2013, 4: 1970

4 Wang K, Meng Q, Zhang Y, Wei Z, Miao M. High-performance two-ply yarn supercapacitors based on carbon nanotubes and polyaniline nanowire arrays. Adv Mater, 2013, 25: 1494-1498

5 Sun G, Zhou J, Yu F, et al. Electrochemical capacitive properties of CNT fibers spun from vertically aligned CNT arrays. J Solid State Electr, 2012, 16: 1775-1780

6 Sun G, Liu J, Zheng L, Huang W, Zhang H. Preparation of weavable, all-carbon fibers for non-volatile memory devices. Angew Chem Int Ed, 2013, 125: 13593-13597

7 Lin $\mathrm{H}$, Weng W, Ren J, et al. Twisted aligned carbon nanotube/ silicon composite fiber anode for flexible wire-shaped lithium-ion battery. Adv Mater, 2014, 26: 1217-1222

8 Chen T, Wang S, Yang Z, et al. Flexible, light-weight, ultrastrong, and semiconductive carbon nanotube fibers for a highly efficient solar cell. Angew Chem Int Ed, 2011, 50: 1815-1819

9 Chen T, Qiu L, Cai Z, et al. Intertwined aligned carbon nanotube fiber based dye-sensitized solar cells. Nano Lett, 2012, 12: 2568-2572

10 Chen T, Qiu LB, Kia HG, Yang ZB, Peng HS. Designing aligned inorganic nanotubes at the electrode interface: towards highly efficient photovoltaic wires. Adv Mater, 2012, 24: 4623-4628

11 Cai F, Chen T, Peng H. All carbon nanotube fiber electrode-based dye-sensitized photovoltaic wire. J Mater Chem, 2012, 22: 1485614860

12 Zhang X, Li Q, Holesinger TG, et al. Ultrastrong, stiff, and lightweight carbon-nanotube fibers. Adv Mater, 2007, 19: 4198-4201

13 Li QW, Li Y, Zhang XF, et al. Structure-dependent electrical properties of carbon nanotube fibers. Adv Mater, 2007, 19: 3358-3363

14 Li QW, Zhang XF, DePaula RF, et al. Sustained growth of ultralong carbon nanotube arrays for fiber spinning. Adv Mater, 2006, 18: 3160-3163 
15 Sun X, Chen T, Yang Z, Peng H. The alignment of carbon nanotubes: an effective route to extend their excellent properties to macroscopic scale. Acc Chem Res, 2012, 46: 539-549

16 Lima MD, Fang S, Lepró X. et al. Biscrolling nanotube sheets and functional guests into yarns. Science, 2011, 331: 51-55

17 Cui HF, Ye JS, Zhang WD, Wang J, Sheu FS. Electrocatalytic reduction of oxygen by a platinum nanoparticle/carbon nanotube composite electrode. JElectroanalChem, 2005, 577: 295-302

18 Yang Z, Sun H, Chen T. et al. Photovoltaic wire derived from a graphene composite fiber achieving an $8.45 \%$ energy conversion efficiency. Angew Chem Int Ed, 2013, 125: 7693-7696

19 Duarte M, Pilla A, Sieben J, Mayer C. Platinum particles electrodeposition on carbon substrates. Electrochem Commun, 2006, 8: 159-164

20 Sun H, You X, Deng J, et al. Novel graphene/carbon nanotube composite fibers for efficient wire-shaped miniature energy devices. Adv Mater, 2014, 26: 2868-2873

21 Gong $\mathrm{F}$, Wang $\mathrm{H}, \mathrm{Xu}$ X, Zhou G, Wang ZS. In situ growth of $\mathrm{Co}_{0.85} \mathrm{Se}$ and $\mathrm{Ni}_{0.85} \mathrm{Se}$ on conductive substrates as high-performance counter electrodes for dye-sensitized solar cells. J Am Chem Soc, 2012, 134: 10953-10958

22 Sun H, You X, Jiang YS, et al. Self-healable electrically conducting wires for wearable microelectronics. Angew Chem Int Ed, 2014, 53:
9526-9531

23 Peng HS, Sun XM, Cai FJ, et al. Electrochromatic carbon nanotube/polydiacetylene nanocomposite fibres. Nat Nanotech, 2009, 4: $738-741$

Acknowledgements This work was supported by the Ministry of Science and Technology of China (2011CB932503), the National Natural Science Foundation of China (21225417), STCSM (12nm0503200), Fok Ying Tong Education Foundation, the Program for Special Appointments of Professors at Shanghai Institutions of Higher Learning, and the Program for Outstanding Young Scholars from the Organization Department of the CPC Central Committee.

Author contributions Jiang YS, Sun H and Peng HS designed the experiments. Peng HS supervised and directed the project. Jiang YS and Sun $\mathrm{H}$ synthesized the materials, fabricated the devices and characterized the device performances. All authors contributed to analyzing the data, discussing the results and writing the manuscript.

Conflict of interest The authors declare that they have no conflict of interest.

Supplementary information Experimental details and supplementary data are available in the online version of the paper.
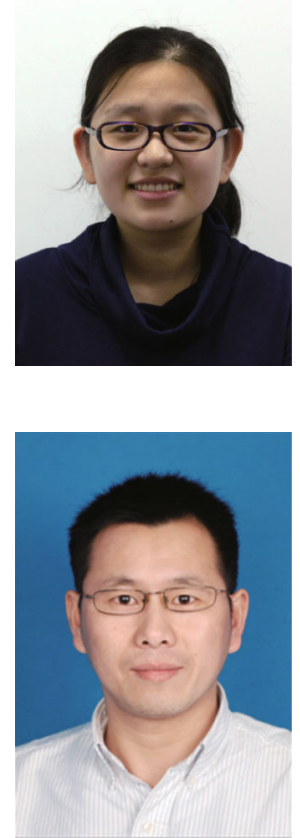

YiShu Jiang is currently an undergraduate student majoring in chemistry at Fudan University. Her ressearch interest focuses on fiber-shaped devices for energy harvesting and storage.

HuiSheng Peng is currently a professor at the Department of Macromolecular Science and Laboratory of Advanced Materials, Fudan University. He received his BSc degree in Polymer Materials at Donghua University (China) in 1999, MSc degree in Macromolecular Chemistry and Physics at Fudan University (China) in 2003 and PhD in Chemical Engineering at Tulane University (USA) in 2006. He then worked at Los Alamos National Laboratory before joining Fudan University in 2008. His research focuses on the development of miniature fiber-shaped solar cells, lithium ion batteries and supercapacitors. He has published more than 110 peer-reviewed papers.

中文摘要 本文利用电化学沉积法成功制备出铂纳米粒子修饰的取向碳纳米管纤维, 并对铂含量进行了有效调控. 铂纳米粒子均匀沉 积于取向碳纳米管纤维表面, 与没有取向纳米结构的其他纤维材料(如碳纤维)相比, 更有效的提高了对 $\mathrm{I}_{3}^{-} / \mathrm{I}^{-}$氧化还原反应的催化活性. 基于铂修饰的取向碳纳米管纤维作为对电极构建的纤维状染料敏化太阳能电池获得了高达 $8.10 \%$ 的能量转换效率, 远高于基于取向碳 纳米管纤维及铂修饰的碳纤维获得的 $4.91 \%$ 和 $5.50 \%$ 的能量转换效率. 